\title{
Pengukuran Perangkat Lunak Untuk Effort Estimation dengan Teknik Pembelajaran Mesin
}

\author{
Maria Rosario Borroek ${ }^{1}$, Errissya Rasywir², Yovi Pratama ${ }^{2}$ \\ ${ }^{1}$ Sistem Informasi, Program Studi Imu Komputer, Universitas Dinamika Bangsa, Jambi, Indonesia \\ ${ }^{2}$ Teknik Informatika, Program Studi Imu Komputer, Universitas Dinamika Bangsa, Jambi, Indonesia \\ Email: ${ }^{1}$ diamar_ros@yahoo.com, ${ }^{2}$ errissya.rasywir@gmail.com, ${ }^{3}$ yovi.pratama@gmail.com
}

\begin{abstract}
Abstrak-Software effort estimation adalah mengestimasi sejumlah sumber daya yang diperlukan dalam mengembangkan perangkat lunak. Untuk itu software effort estimation merupakan hal yang penting sehingga perlu melihat pengaruh pengukuran perangkat lunak terhadap software effort estimation yang dilakukan dengan teknik pembelajaran mesin.Berdasarkan hal tersebut peneliti mencoba membangun sebuah sistem yang mampumelakukan pengukuran perangkat lunak.Pada penelitianinidilakukan eksperimen terhadap teknik pengukuran perangkat lunak (FPA, FPA dengan Sugeno fuzzy dan FPA dengan mamdani fuzzy). Tiga Jenis teknik tersebut dikomparasi dengan tiga data proyek untuk selanjutnya dilakukan software effort estimation.Untuk evaluasi, penelitianini melakukan evaluasi menggunakan penilaian Developer sebagai Sistem Anal is Proyek.Hasil penelitian bahwa nilai LOC dan effort pada sebuah sistem yang sama dapat berbeda jika dihitung dengan penggunaan metode FPA, FPA Mamdany fuzzy dan FPA Sugeno Fuzzy. Nilai LOC dan Effort tertinggi dihasilkan oleh FPA Mamdany Fuzzy pada Proyek DUMAS POLDA SUMSEL. Sedangkan nilai effort terendah dan LOC terendah dihasilkan oleh FPA Sugeno Fuzzy. Hal ini dapat ditelusuri dari mekanisme perhitungan yang dilakukan oleh FPA Sugeno Fuzzy dimana metode ini sama sekali tidak menghitung nilai input, output, file, query dan interface. Perhitungan FPA Sugeno fuzzy dilakukan dengan cara kasar hanya menilai dari kesulitan pembuatan sistem. Untuk menaikkan harga suatu proyek agar dihargai lebih tinggi Metode FPA Mamdani Fuzzy lebih direkomendasikan.
\end{abstract}

Kata Kunci: FPA, Mamdani, Sugeno, Fuzzy, Effort

Abstract-Software effort estimation is to estimate the amount of resources needed in developing the software. For that software effort estimation is important so need to see the effect of software measurement to software effort estimation which is done by machine learning technique. Based on this the researcher tries to build a system capable of measuring software. In this study experiments on software measurement techniques (FPA, FPA with Sugeno fuzzy and FPA with mamdani fuzzy). The three types of techniques are compared with the three project data for further software effort estimation. For evaluation, this study evaluates using the assessment of the Developeras Analyst of the Project. The results of the study that the LOC and effort values on a similar system can be different if calculated by the use of FPA, Fam Mamdany fuzzy and FPA Sugeno Fuzzy. The highest LOC and Effort values are generated by FPA Mamdany Fuzzy on Project DUMAS POLDA SUMSEL. While the lowest effort value and lowest LOC produced by FPA Sugeno Fuzzy. This can be traced from the calculation mechanisms performed by FPA Sugeno Fuzzy where this method does not count the input, output, file, query and interface values at all. The calculation of FPA Sugeno fuzzy is done by roughly judging only from the difficulty of making the system. To raise the price of a project in order to be rewarded higher FAT methods Mamdani Fuzzy is recommended.

Keywords: FPA, Mamdani, Sugeno, Fuzzy, Effort.

\section{PENDAHULUAN}

Software effort estimation atau estimasi usaha perangkat lunak adalah bagian penting dari sebuah manajemen proyek.Estimasi yang akurat membantu kita menyelesaikan proyek dalam waktu dan anggaran yang telah ditentukan.Terdapat berbagai teknik, model estimasi dan tools untuk estimasi perangkat lunak [1], [2].

Berbagai penelitian terdahulu telah melakukan software effort estimation dengan berbagai metode, baik metode non pembelajaran mesin maupun pembelajaran mesin. Beberapa metode estimasi usaha perangkat lunak dengan metode non pembelajaran mesinantara lain SLIM, COCOMO, use case point, dan metode analogi sherpped. Penelitian software effort estimation yang dikembangkan dengan pembelajaran mesin antara lain penggunaan jaringan syaraf tiruan [3], supportvector machine [4], [5], nä̈ve bayes; k-nearest neighbor [2], fuzzy; serta liner regression [6]-[8]. Kemudian penelitian eksperimen Seleksi Fitur Pada Parameter Proyek Untuk Software Effort Estimation dengan K-Nearest Neighbors berhasil menurunkan nilai error estimasi [1], [3], [9]. Selain itu penulis juga pernah melakukan perhitungan besaran fungsional dengan menggunakan COSMIC dataset yang dikemas dengan Case Based[10], [11]. Hasil penelitian tersebut menemukan bahwasoftware effort estimation yang dilakukan dengan teknik pembelajaran mesin menghasilkan nilai estimasi yang lebih baik dengan nilai error yang lebih kecil dibanding dengan teknik non pembelajaran mesin.

Software effort estimation sangat tergantung pada variabel perhitungan dari ukuran perangkat lunak[12].Semakin akurat mengestimasi pengukuran perangkat lunak maka semakin akurat dalam software effort estimation [3]. Dalam melakukan pengukuran perangkat lunak terdapat berbagai metode yang dapat digunakanmisalnya line of code (LOC), function point analysis metoda FPAdan COSMIC, FPA dengan Mamdani Fuzzy [4].

Tantangan yang dihadapi oleh pengembang adalah bagaimana melakukan pengukuran perangkat lunaksecara akurat.Pengukuran perangkat lunak dapat menentukan biaya perangkat lunak yang terlampir pada tahap awal proyek pengembangan software.Namun, pengukuran perangkat lunaksulit dilakukan karena nilainya 
tidak menentu dan tidak akurat. Hal tersebut karena hanya sedikit detail yang diketahui tentang proyek di awal pengembangan software. Terdapat beberapa kelemahan dari metode pengukuran perangkat lunak formal antara lain nilai pengukuran yang bergantung pada desain atau impementasi sistem, proses pengukuran software yang belum terdapatnya standar pengukurnya. Berdasarkan hal tersebut maka penelitian ini dilakukan untuk menemukan metode pengukuranterbaik dalam melakukan software effort estimation dengan teknik pembelajaran mesin.

\section{METODE PENELITIAN}

Berikut merupakan tahapan penulis dalam melakukan penelitian, yaitu:

1. Penelitian Awal

Pada tahapan ini dikumpulkan bahan penelitian dari berbagai sumber pustaka, seperti buku, jurnal (baik cetak maupun online), prosiding, majalah, artikel dan sumber lain yang relevan. Masalah yang dibahas adalah bagaimana pengaruh metode pengukuran perangkat lunak terhadap software effort estimation yang dilakukan dengan teknik pembelajaran mesin, metode pengukuran perangkat lunakapa yang paling akurat dalam mengukur software serta bagaimana melakukan pengukuran perangkat lunak secara otomatis. Teori yang diambil tentang software estimation effort, pengukuran perangkat lunak, FPA, FPA dengan Sugeno fuzzy danFPA dengan mamdani fuzzy, k-nearest neighbor dan SVM yang akan diujikan guna melakukan eksperimen yang dibahas dalam penelitian ini.

2. Pengumpulan Data

Data diambil dari beberapa proyek perangkat lunak. Proyek tesebut antara lain: Sistem Pengaduan Masyarakat POLDA (DUMAS Sumsel), SIMPEG BKD OKI Sumsel dan RSFD Activity System (RAS) BTN Pusat Jakarta. Proyek tersebut merupakan proyek yang sudah final dan berupa source code dengan Bahasa pemrograman PHP yang dibangun dengan framework codeigniter.

3. Melakukan Software Sizing untuk Software Effort Estimation

Kegiatan ini berupa pengukuran perangkat lunakyang mana hasil pengukuran tersebut digunakan dalam melakukan software effort estimation. Kemudian hasil effort estimationakan dievaluasi. Berikut gambar 2 adalah gambaran secara umum mengenai skema sistem penelitian yang dilakukan:

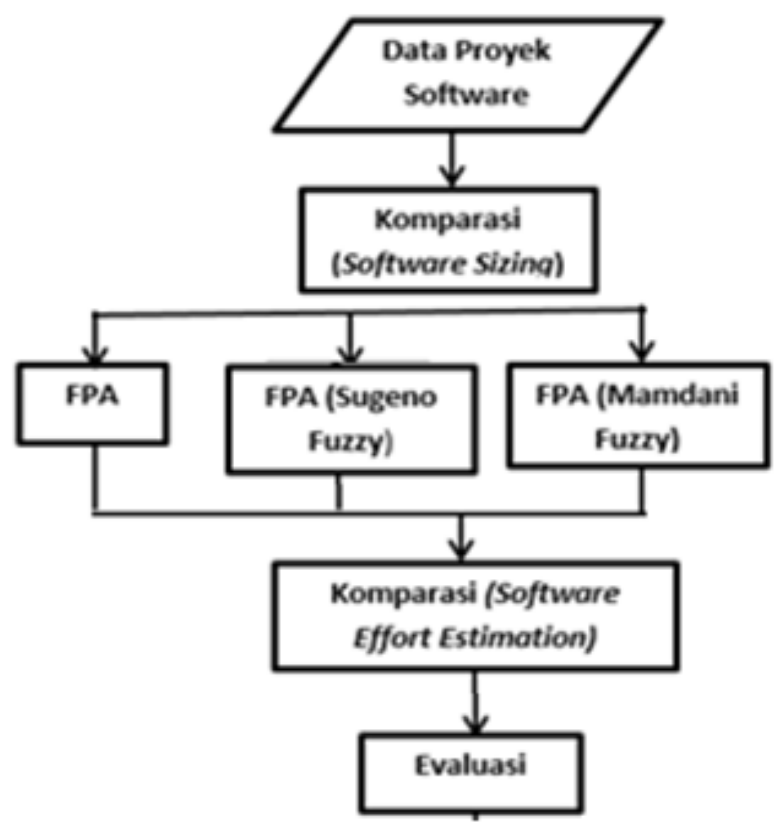

Gambar 1. Gambar Alur Riset

4. Melakukan Perbandingan Metoda

Kegiatan ini melakukan eksperimen dengan cara melakukan komparasi terhadap beberapa metode pengukuran perangkat lunak(FPA, FPA dengan Sugeno fuzzy dan FPA dengan mamdani fuzzy). Kemudian hasil pengukuran dengan 3 metode tersebut dilakukan software effort estimation. Alur Eksperimen telah dijelaskan dalam sistem eksperimen pada gambar gambar 2 di atas.

5. Evaluasi Hasil

Pada kegiatan ini dilakukan evaluasi dan analisis terhadap hasil estimasi proyek perangkat lunak dengan menggunakan sistem eksperimen penelitian yang telah dibangun. Hasil evaluasi dianalisis yakni dengan mengukur nilai Effort. 
JURNAL MEDIA INFORMATIKA BUDIDARMA

Volume 4, Nomor 2, April 2020, Page 445-452

ISSN 2614-5278 (media cetak), ISSN 2548-8368 (media online)

Available Online at https://ejurnal.stmik-budidarma.ac.id/index.php/mib

DOI 10.30865/mib.v4i2.2083

\section{HASIL DAN PEMBAHASAN}

\subsection{Analisis Komparasi Proyek dan Metode Software Sizing}

Proyek yang akan dianalisis pada penelitian ini, antara lain:

1. Sistem Pengaduan Masyarakat POLDA Sumsel (Sumatera Selatan)

2. Sistem Kepegawaian kabupaten Ogan Komering Ilir (Sumatera Selatan)

3. RSFD Activity System pada Kantor BTN Pusat Jakarta

Dengan metode software sizing yang digunakan adalah 3 jenis metode yakni:

1. Function Point Analysis metoda FPA

2. FPA dengan Sugeno Fuzzy

3. FPA dengan Mamdani Fuzzy

Data-data proyek yang digunakan antara lain disajikan dalam:

1. Tabel Line of Code dari Setiap Proyek tersebut

2. Diagram Use Case setiap Proyek

3. Tampilan Sistem setiap Proyek

Untuk perhitungan Line of Code(LOC) setiap proyek yang dikomparasi dilakukan secara otomatis dengan menggunakan sebuah function penghitung LOC. Berikut adalah isi dari function LOC yang digunakan:

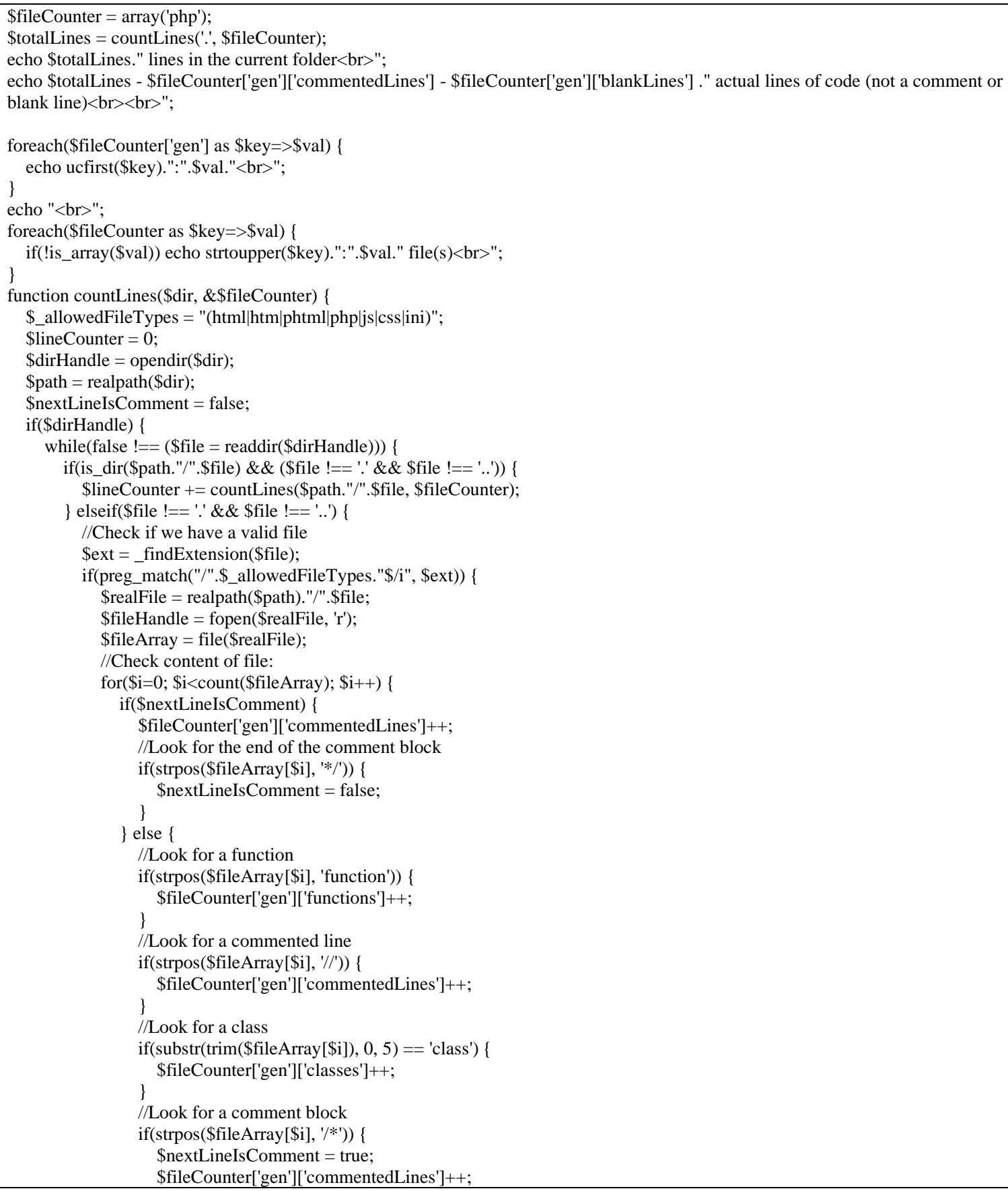




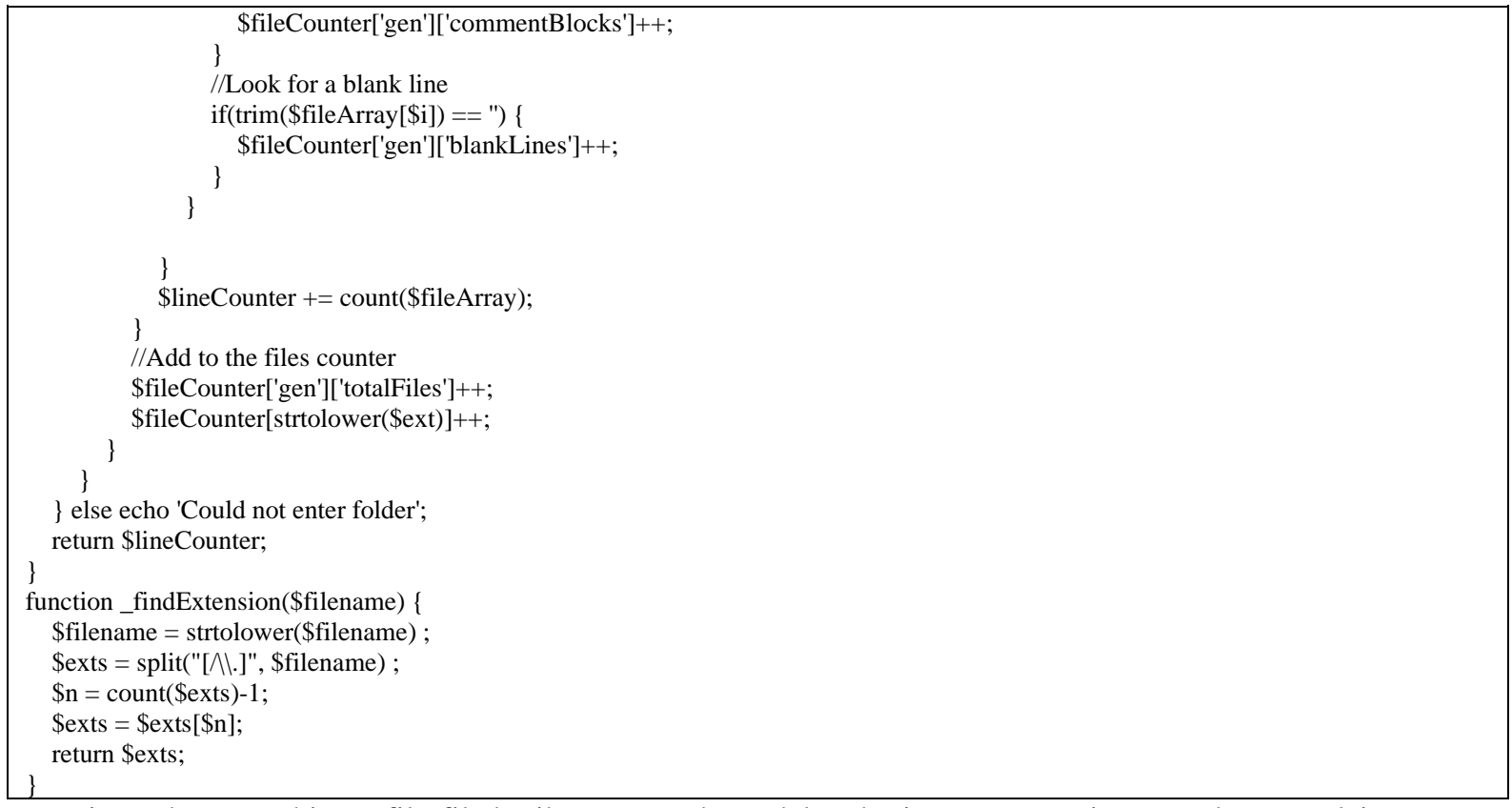

Fungsi tersebut menghitung file-file berikut yang tedapat dalam baris program setiap proyek, antara lain:

Tabel 1. File Yang Dihitung Otomatis Oleh Function LOC Counter

\begin{tabular}{ll}
\multicolumn{1}{c}{ FILE YANG DIHITUNG OTOMATIS OLEH FUNCTION LOC COUNTER } \\
1. lines in the current folder & 2. PHP \\
3. actual lines of code (not a comment or blank line) & 4. JPG \\
5. TotalFiles & 6. CGIECHO \\
7. BlankLine & 8. CGIEMAIL \\
9. CommentedLines & 10. CGI \\
11. Functions & 12. CSS \\
13. Classes & 14. PNG \\
15. CommentBlocks & 16. JS:114 file(s) \\
17. php file & 18. TTF:2 file(s) \\
19. HTACCESS & 20. JPEG:2 file(s) \\
21. GIF & 22. DB \\
23. SQL & 24. ERROR_LOG \\
25. HTML &
\end{tabular}

Parameter yang dinilai dalam perhitungan FPA diperoleh dari perhitungan file di atas dan nilai berikut:

Tabel 2. Parameter Perhitungan TUFP

\begin{tabular}{ll}
\hline \multicolumn{1}{c}{ Parameter } & \multicolumn{1}{c}{ Keterangan } \\
\hline External Input (EI) & Interface untuk memasukan data pada aplikasi. \\
External Output (EO) & output yang dihasilkan. \\
External Inquiry (EQ) & query terhadap data yang tersimpan \\
InternalLogical File (ILF) & logik penyimpan data. \\
ExternalInterface File (EIF) & komunikasi data pada parangkat/mesin yang lain. \\
\hline
\end{tabular}

\subsection{Analisis Nilai Line Of Code Software}

Tabel 3. Analisis LOC Sistem Pengaduan Masyarakat POLDA (DUMAS POLDA Sumsel)

\begin{tabular}{lc}
\hline \multicolumn{2}{c}{ Baris Koding Interface Sistem } \\
\hline 139563 lines in the current folder & PHP:231 file(s) \\
93415 actual lines of code (not a comment & JPG:49 file(s) \\
or blank line) & CGIECHO:3 file(s) \\
TotalFiles:596 & CGIEMAIL:3 file(s) \\
BlankLines:15854 & CGI:6 file(s) \\
CommentedLines:30294 & CSS:14 file(s) \\
Functions:8393 & PNG:70 file(s) \\
Classes:60 & JS:114 file(s) \\
CommentBlocks:565 & TTF:2 file(s) \\
0:php file(s) & JPEG:2 file(s) \\
\hline
\end{tabular}




\begin{tabular}{ll}
\hline HTACCESS:6 file(s) & DB:2 file(s) \\
GIF:46 file(s) & ERROR_LOG:1 file(s) \\
SQL:4 file(s) & \\
HTML:43 file(s) & \\
\hline
\end{tabular}

Tabel 4. Perhitungan Total Udjasted Function Point (TUFP) Sistem Pengaduan Masyarakat POLDA (DUMAS POLDA Sumsel)

\begin{tabular}{|c|c|c|c|c|c|c|}
\hline \multirow{3}{*}{$\begin{array}{l}\text { TUFP } \\
\text { Decription }\end{array}$} & \multicolumn{6}{|c|}{ Complexity } \\
\hline & \multicolumn{2}{|c|}{ Low } & \multicolumn{2}{|c|}{ Medium } & \multicolumn{2}{|c|}{ High } \\
\hline & Point & Bobot & Point & Bobot & Point & Bobot \\
\hline External Input (EI) & 5 & 3 & 6 & 4 & 3 & 6 \\
\hline External Output (EO) & 0 & 4 & 3 & 5 & 0 & 7 \\
\hline External Inquiry (EQ) & 0 & 3 & 4 & 4 & 0 & 6 \\
\hline InternalLogical File (ILF) & 0 & 7 & 596 & 10 & 0 & 15 \\
\hline ExternalInterface File (EIF) & 0 & 6 & 0 & 7 & 0 & 10 \\
\hline
\end{tabular}

Tabel 5. Analisis LOC Sistem Kepegawaian BKD Ogan Komering Ilir (SIMPEG BKD OKI Sumsel)

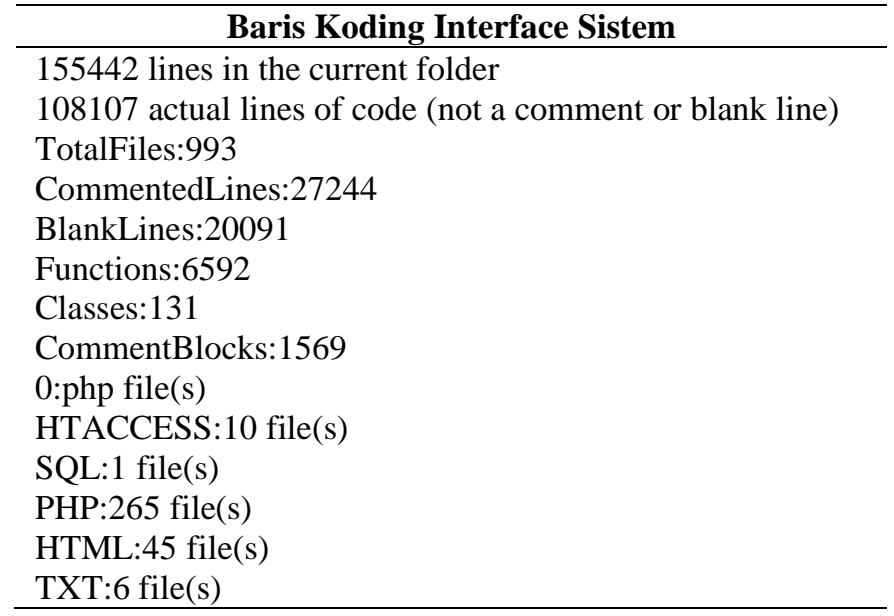

Tabel 6. Perhitungan Total Udjasted Function Point (TUFP) Sistem Kepegawaian BKD Ogan Komering Ilir (SIMPEG BKD OKI Sumsel)

\begin{tabular}{lllllll}
\hline \multicolumn{1}{c}{ TUFP } & \multicolumn{4}{c}{ Low } & \multicolumn{2}{c}{ Complexity } \\
Medium & \multicolumn{2}{c}{ High } \\
\multicolumn{1}{c}{ Decription } & Point & Bobot & Point & Bobot & Point & Bobot \\
\hline External Input (EI) & 5 & 3 & 5 & 4 & 3 & 6 \\
External Output (EO) & 0 & 4 & 3 & 5 & 0 & 7 \\
External Inquiry (EQ) & 0 & 3 & 1 & 4 & 0 & 6 \\
InternalLogical File (ILF) & 0 & 7 & 993 & 10 & 0 & 15 \\
ExternalInterface File (EIF) & 0 & 6 & 0 & 7 & 0 & 10 \\
\hline
\end{tabular}

Tabel 7. Nilai Line Of Code ProyekRSFD Activity System (RAS) BTN Pusat Jakarta

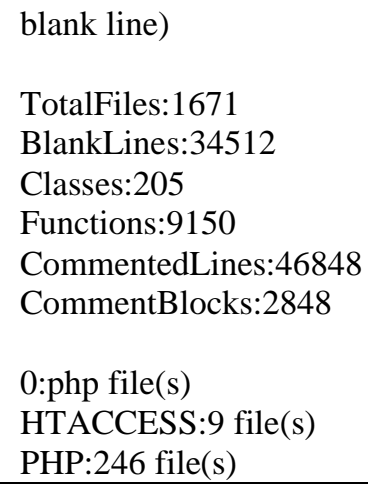

XLSX:12 file(s)
PNG:215 file(s)
CSS:92 file(s)
GIF:106 file(s)
JS:554 file(s)
SH:1 file(s)
TXT:17 file(s)
HTM:34 file(s)
SWF:5 file(s)
JPG:76 file(s)
SWC:1 file(s)
AS:2 file(s)
PSD:4 file(s)
GZ:1 file(s)

MD:1 file(s) DOCX:23 file(s) MMAP:4 file(s)

PPT:1 file(s) PDF:7 file(s) RAR:3 file(s) SQL:2 file(s) XLS:13 file(s) JPEG:1 file(s) TTF:3 file(s) EOT:1 file(s) SVG:1 file(s) WOFF: 1 file(s) OTF: 1 file(s) 


HTML:223 file(s) GITIGNORE:1 file(s) $\quad$ LESS:9 file(s)

TIF:1 file(s)

Tabel 8. Nilai Line Of Code Proyek RSFD Activity System (RAS) BTN Pusat Jakarta

\begin{tabular}{llllllll}
\hline TUFP & \multicolumn{9}{c}{ Low } & \multicolumn{2}{c}{$\begin{array}{c}\text { Medium } \\
\text { Pexity }\end{array}$} & \multicolumn{2}{c}{ High } \\
\multicolumn{1}{c}{ Decription } & Point & Bobot & Point & Bobot & Point & Bobot \\
\hline External Input (EI) & 12 & 3 & 5 & 4 & 6 & 6 \\
External Output (EO) & 0 & 4 & 23 & 5 & 0 & 7 \\
External Inquiry (EQ) & 0 & 3 & 0 & 4 & 0 & 6 \\
InternalLogical File (ILF) & 0 & 7 & 1671 & 10 & 0 & 15 \\
ExternalInterface File (EIF) & 0 & 6 & 0 & 7 & 0 & 10 \\
\hline
\end{tabular}

Keterangan:

1. Data External Input (EI) : Jumlah file Interface untuk memasukan data pada aplikasi.

a. Low : Terdapat12 Modul untuk task input pada sistem yang mudah dibangun.

b. Medium : Terdapat 5 Modul untuk task input pada sistem yang medium dibangun.

c. High : Terdapat 6 Modul untuk task input pada sistem yang sulit dibangun.

2. Data External Output (EO): Jumlah output yang dihasilkan.

a. Low : Terdapat 0 Modul untuk task input pada sistem yang mudah dibangun.

b. Medium : Terdapat 23 Modul task input pada sistem yang medium dibangun.

c. High : Terdapat 0 Modul untuk task input pada sistem yang sulit dibangun.

3. External Inquiry (EQ) : Jumlah query terhadap data yang tersimpan

a. Low : Terdapat 0 Modul untuk task input pada sistem yang mudah dibangun.

b. Medium : Terdapat 4 Modul untuk task input pada sistem yang medium dibangun.

c. High : Terdapat 0 Modul untuk task input pada sistem yang sulit dibangun.

4. Internal Logical File(ILF) : Jumlah file yang terdapat dalam sistem.

a. Low : Terdapat 0 Modul untuk task input pada sistem yang mudah dibangun.

b. Medium : Terdapat 1671 Modul untuk task input pada sistem yang medium dibangun.

c. High : Terdapat 0 Modul untuk task input pada sistem yang sulit dibangun.

5. External Interface File (EIF): Keterhubungan sistem dengan device lain (0 jika standalone)

a. Low : Terdapat 0 Modul EIF untuk task input pada sistem yang mudah dibangun.

b. Medium : Terdapat 0 Modul EIF untuk task input pada sistem yang medium dibangun.

c. High : Terdapat 0 Modul EIF untuk task input pada sistem yang sulit dibangun.

\subsection{Analisis Perhitungan Keseluruhan Sistem dan Metode}

Pada sub bab ini dijelaskan analisis perhitungan sistem DUMAS POLDA SUMSEL, SIMPEG BKD OKI SUMSEL dan RAS BTN PUSAT Jakarta. Analisis yang dilakukan meliputi nilai Line Of Codes (LOC) dan Effort pada ketiga sistem yang diujicobakan. Berikut tabel 103 merupakan analisis keseluruhan sistem dan metode yang diujicobakan.

Tabel 9. Analisis Perhitungan Keseluruhan Sistem dan Metode

\begin{tabular}{|c|c|c|c|c|}
\hline Metode & No & Proyek & $\begin{array}{l}\text { Lines of Codes } \\
\text { (LOC) }\end{array}$ & Effort \\
\hline \multirow[t]{3}{*}{ FPA } & 1 & $\begin{array}{l}\text { Sistem Pengaduan Masyarakat } \\
\text { POLDA (DUMAS Sumsel) }\end{array}$ & $467.994,24$ & $35.145 .647,83$ \\
\hline & 2 & SIMPEG BKD OKI Sumsel & $779.255,82$ & $63.819 .856,39$ \\
\hline & 3 & $\begin{array}{l}\text { RSFD Activity System (RAS) BTN } \\
\text { Pusat Jakarta }\end{array}$ & $1.666 .732,87$ & 1.553364 .512 \\
\hline \multirow[t]{3}{*}{$\begin{array}{l}\text { FPA Mamdani } \\
\text { Fuzzy }\end{array}$} & 1 & $\begin{array}{l}\text { Sistem Pengaduan Masyarakat } \\
\text { POLDA (DUMAS Sumsel) }\end{array}$ & $24.384 .583,44$ & 3.586.039.820 \\
\hline & 2 & SIMPEG BKD OKI Sumsel & $40.350 .873,56$ & 6.464 .547 .040 \\
\hline & 3 & $\begin{array}{l}\text { RSFD Activity System (RAS) BTN } \\
\text { Pusat Jakarta }\end{array}$ & $82,926,477,06$ & 15.016.240.703 \\
\hline \multirow[t]{3}{*}{$\begin{array}{l}\text { FPA Sugeno } \\
\text { Fuzzy }\end{array}$} & 1 & $\begin{array}{l}\text { Sistem Pengaduan Masyarakat } \\
\text { POLDA (DUMAS Sumsel) }\end{array}$ & $7.334,1294$ & $271,736,5039$ \\
\hline & 2 & SIMPEG BKD OKI Sumsel & $7.281,087$ & $269.438,5524$ \\
\hline & 3 & $\begin{array}{l}\text { RSFD Activity System (RAS) BTN } \\
\text { Pusat Jakarta }\end{array}$ & $11.625,603$ & $465.828,7406$ \\
\hline
\end{tabular}


Dari tabel di atas dapat dilihat bahwa nilai LOC dan effort pada sebuah sistem yang sama dapat berbeda jika dihitung dengan penggunaan metode FPA, FPA Mamdany fuzzy dan FPA Sugeno Fuzzy. Nilai LOC tertinggi dihasilkan oleh FPA Mamdany Fuzzy pada Sistem Pengaduan Masyarakat POLDA (DUMAS Sumsel). Begitu juga nilai Effort tertinggi, juga dihasilkan FPA Mamdany Fuzzy pada Sistem Pengaduan Masyarakat POLDA (DUMAS Sumsel). Sedangkan Nilai effort terendah sekaligus LOC terendah dihasilkan oleh FPA Sugeno Fuzzy. Hal ini dapat ditelusuri dari mekanisme perhitungan yang dilakukan oleh FPA Sugeno Fuzzy dimana metode ini sama sekali tidak menghitung nilai input, output, file, query dan interface. Perhitungan FPA Sugeno fuzzy dilakukan dengan cara kasar hanya menilai dari kesulitan pembuatan sistem.

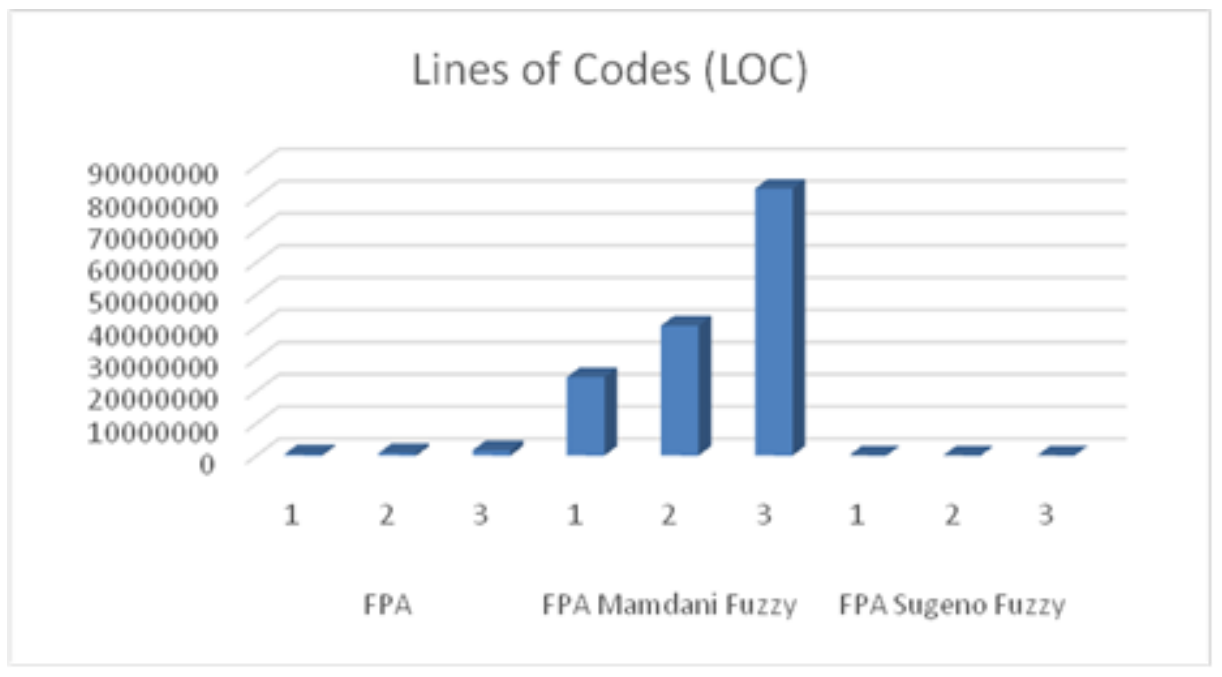

Gambar 2. Kurva Perbandingan Nilai LOC yang dihasilkan Tiga Proyek dengan Tiga Metode (FPA, FPA Mamadani Fuzzy dan FPA Sugeno Fuzzy)

Dari gambar 2 yang dihasilkan kurva di atas dapat dilihat bahwa Nilai LOC yang dihasilkan sangat berbeda dan sangat signifikan. Nilai tertinggi dihasilkan oleh FPA Mamdani Fuzzy. Terendah dihasilkan FPA Sugeno Fuzzy

\section{KESIMPULAN}

Adapun kesimpulan dari penelitian ini adalah bahwa nilai LOC dan effort pada sebuah sistem yang sama dapat berbeda jika dihitung dengan penggunaan metode FPA, FPA Mamdany fuzzy dan FPA Sugeno Fuzzy. Nilai LOC tertinggi dihasilkan oleh FPA Mamdany Fuzzy pada Sistem Pengaduan Masyarakat POLDA (DUMAS POLDA Sumsel). Nilai Effort tertinggi, juga dihasilkan FPA Mamdany Fuzzy pada Sistem Pengaduan Masyarakat POLDA (DUMAS POLDA Sumsel). Sedangkan nilai effort terendah dan LOC terendah dihasilkan oleh FPA Sugeno Fuzzy. Hal ini dapat ditelusuri dari mekanisme perhitungan yang dilakukan oleh FPA Sugeno Fuzzy dimana metode ini sama sekali tidak menghitung nilai input, output, file, query dan interface. Perhitungan FPA Sugeno fuzzy dilakukan dengan cara kasar hanya menilai dari kesulitan pembuatan sistem. Walaupun FPA Sugeno menghasilkan nilai effort yang rendah, tapi nilai yang dihasilkan lebih merata. Berdasarkan hasil penelitian ini, untuk menaikkan harga suatu proyek agar dihargai lebih tinggi Metode FPA Mamdani Fuzzy lebih direkomendasikan. Selanjutnya, peneitian ini perlu dilakukan eksperimen dengan jumlah proyek yang lebih banyak serta dapat dikembangkan kembali dengan menggunakan metode perhitungan LOC dan Effort lainnya.

\section{REFERENCES}

[1] Y. Pratama and E. Rasywir, "Automatic Cost Estimation Analysis on Datawarehouse Project with Modified Analogy Based Method," in Proceedings of 2018 International Conference on Electrical Engineering and Computer Science, ICECOS 2018, 2019, pp. 171-176.

[2] R. Sarno and J. Sidabutar, "Comparison of Different Neural Network Architectures for Software Cost Estimation," in International Conference on Computer, Control, Informatics and Its Applications Comparison, 2015, pp. 68-73.

[3] F. Fachruddin and Y. Pratama, "Eksperimen Seleksi Fitur Pada Parameter Proyek Untuk Software Effort Estimation dengan K-Nearest Neighbor,” J. Inform. J. Pengemb. IT, vol. 2, no. 2, pp. 53-62, 2017.

[4] B. Demir and L. Bruzzone, "A Novel Active Learning Method in Relevance Feedback for Content-Based Remote Sensing Image Retrieval," Geosci. Remote Sensing, IEEE Trans., vol. 53, no. 5, pp. 2323-2334, 2015.

[5] S. Kumari and S. Pushkar, "Comparison and Analysis of Different Software Cost Estimation Methods," Int. J. Adv. Comput. Sci. Appl., vol. 4, no. 1, pp. 153-157, 2013.

[6] J. W. S. L. L. Tang, "Software, Improve Analogy-based Estimation, Effort Principal, Using Analysis, Components Weighting," in Software Engineering Conference, 2011, vol. 16, no. 2, pp. 11-12.

[7] Y. F. Li, M. Xie, and T. N. Goh, "A study of project selection and feature weighting for analogy based software cost 
JURNAL MEDIA INFORMATIKA BUDIDARMA

Volume 4, Nomor 2, April 2020, Page 445-452

ISSN 2614-5278 (media cetak), ISSN 2548-8368 (media online)

Available Online at https://ejurnal.stmik-budidarma.ac.id/index.php/mib

DOI 10.30865/mib.v4i2.2083

estimation," J. Syst. Softw., vol. 82, no. 2, pp. 241-252, 2009.

[8] M. Azzeh, "A replicated assessment and comparison of adaptation techniques for analogy-based effort estimation," Empir. Softw. Eng., vol. 17, no. 1-2, pp. 90-127, 2012.

[9] N. H. Chiu and S. J. Huang, "The adjusted analogy-based software effort estimation based on similarity distances," $J$. Syst. Softw., vol. 80, no. 4, pp. 628-640, 2007.

[10] A. Idri, F. A. Amazal, and A. Abran, "Analogy-based software development effort estimation: A systematic mapping and review," Inf. Softw. Technol., vol. 58, pp. 206-230, 2015.

[11] A. K. Bardsiri and S. M. Hashemi, "Software Effort Estimation : A Survey of Well-known Approaches," Ijcse, vol. 3, no. 01, pp. 46-50, 2014.

[12] S. Kaur, S. Assistant, J. Kaur, S. Faculty, N. Chandigarh, and S. Singh, "Effect of Data Preprocessing on Software Effort Estimation," Int. J. Comput. Appl., vol. 69, no. 25, pp. 975-8887, 2013. 